\title{
La teoría freudiana de la histeria. Una reconstrucción nominalista*
}

\author{
The Freudian Theory of Hysteria. A Nominalist Reconstruction
}

César Lorenzano ${ }^{\dagger}$

\begin{abstract}
Resumen
Dora, una joven de 18 años es llevada por su padre a la consulta de Freud, por tener diversos signos y síntomas sucesivos o conjuntos que casi la imposibilitan: tos nerviosa, ronquera, ataques de apendicitis, etc., que Freud diagnostica como histeria. En el curso del tratamiento, descubre que Dora conoce a fondo la sexualidad humana, incluso las -así llamadas- perversiones, y que está enamorada del señor $\mathrm{K}$, de la señora $\mathrm{K}$, quizás de su padre; mantiene intensas relaciones con otras figuras femeninas, y sueña con casas que se incendian. Al tiempo que narra sus encuentros, Freud construye ante nuestros ojos su concepción psicoanalítica de la histeria. De ese material se extraen siguiendo las distinciones de la concepción estructuralista- sus elementos y leyes fundamentales, describiéndose con ellos a Dora y a los demás casos de histeria que se asemejen a este caso paradigmático. La reconstrucción resultante da cuenta de la teoría freudiana de la histeria, sin apelar -ni comenzar con- la descripción de estructuras matemáticas abstractas, como acontece habitualmente en el estructuralismo. Se trata, en suma, de una reconstrucción de los ejemplares de la teoría, que satisface todos los requerimientos usuales exigidos a un análisis estructural. Se resuelven de esta manera tensiones ontológicas presentes en esta concepción, mostrándose que puede ser expuesta con un monismo ontológico y epistemológico de corte fisicalista y nominalista.
\end{abstract}

Palabras clave: Freud - histeria - psicoanálisis - estructuralismo metateórico - fisicalismo - nominalismo

\begin{abstract}
Dora, an 18-years young girl, goes with her father to Freud's clinic, because of several close to disabling signs and symptoms: "tussi nervosa", aphonia, appendicitis attacks, etc. that Freud diagnoses as hysteria. During the treatment, he discovers that Dora has full knowledge of human sexuality, even of so-called perversions. She is in love with Mr. K, with Mrs. K, probably with her own father, she has intense relationships with other females, and she dreams with houses that catch fire. While retelling their interviews, Freud builds his psychoanalytical conception of hysteria. From that material - and following the distinctions of the structuralist view - I extract its components and fundamental laws, using them to describe Dora and the other cases of hysteria that resemble this paradigmatic case. This reconstruction of the Freudian theory of hysteria is carried without using - or starting with - the description of abstract mathematical structures, as usually happens in structuralism. Briefly, it is a reconstruction of the applications of the theory that complies with all the usual requirements of a structural analysis. In this way I solve some ontological tensions of this conception, showing that it can be developed with an ontological and epistemological monism proper of a physicalist and nominalist approach.
\end{abstract}

Keywords: Freud - hysteria - psychoanalysis - metatheoretical structuralism - physicalism - nominalism

\footnotetext{
* Recibido: 23 de febrero de 2013. Aceptado con revisiones: 10 de junio de 2013.

+ Universidad Nacional de Tres de Febrero (UNTREF), Argentina. Para contactar con el autor, por favor, escribir a: clorenzano@gmail.com.

Metatheoria 6(1)(2015): 1-20. ISSN 1853-2322. eISSN 1853-2330.

(c) Editorial de la Universidad Nacional de Tres de Febrero. Publicado en la República Argentina.
} 


\section{Introducción}

En 1905 Freud publica Análisis fragmentario de una histeria -comúnmente llamado el "Caso Dora"-, escrito en dos semanas cinco años atrás, luego de que el 31 de diciembre de 1900 la paciente pusiera término por propia voluntad al tratamiento.

Debido a que duró menos de tres años, Freud pudo recordarlo por completo y registrarlo a la manera de una historia clínica, la forma canónica con la que los médicos comunican sus casos.

En este escrito sintetizaré las nociones principales que Freud introduce en su artículo, y las relaciones que guardan entre sí. Esta caracterización se presentará mediante una reconstrucción informal que conserva elementos fundamentales de la concepción estructuralista de las teorías, en la inteligencia de que todo lo que expresa puede ser vertido en un lenguaje formal sin que exista pérdida en el proceso.

Aunque Freud no haya seguido fielmente en su texto los apuntes que escribía al final de la consulta o durante ella, asistimos igualmente a un proceso en el que aparecen sucesivamente determinados hechos, y su interpretación mediante un aparato teórico que encuentra su corroboración en nuevos hechos. Somos lectores, gracias a su estilo narrativo, de la génesis de una porción importante de la teoría psicoanalítica; en realidad, de un caso paradigmático de su concepción de la histeria, que es al mismo tiempo el núcleo central, paradigmático, de las demás ampliaciones de la teoría psicoanalítica.

En la medida en que avanza el análisis de Dora vemos cómo Freud descubre -obligado por el material empírico- a formular presunciones teóricas, y a aplicar las ya establecidas, de tal manera que se imbrican y suceden alternativamente el contexto de descubrimiento y el de justificación de las postulaciones fundamentales del psicoanálisis. ${ }^{1}$

Nuestra reconstrucción, por lo tanto, será tanto de lo que le ocurre a Dora, como de la histeria en la concepción freudiana. En el caso Dora aparece encarnado -en acto- el aparato terminológico y legaliforme del psicoanálisis. Como veremos luego, caracterizaremos a la histeria por sus ejemplares, y no por sus modelos abstractos.

Sabemos que es después de escribir sus casos clínicos cuando Freud presenta teóricamente su concepción psicoanalítica, sin demasiadas referencias empíricas. ${ }^{2}$

Si procediéramos a analizar su pensamiento desde estos artículos más tardíos, y tratáramos de reconstruirlo de la forma que es habitual en la concepción estructuralista, empezando por caracterizar los modelos abstractos del núcleo teórico, estaríamos soslayando la enorme carga empírica de su teoría, eso que la hace una concepción fáctica, y no meramente teórica.

$\mathrm{Al}$ reconstruir la histeria por su aplicación paradigmática -el caso Dora- somos consecuentes con el propio Freud, y con el pensamiento médico del que proviene. Al decir más general, no hay enfermedades, sino enfermos; similarmente, diremos que no hay histeria, sino histéricos. No hay sino casos de enfermedades -de histerias- y su conocimiento por parte de los médicos y psicoanalistas. Sin embargo, en los libros de texto se lo simplifica eliminando sus aspectos más particulares, de modo que, al adquirir generalidad, pueda ser aplicado en otros casos, en los que deberá realizarse el proceso inverso de dotarlo de toda la especificidad que poseen. Se trata de un proceso que va desde las historias clínicas particulares a los libros de texto, y de allí a su aplicación a nuevos pacientes, donde se hará constar sus peculiaridades en nuevas historias clínicas.

\footnotetext{
${ }^{1}$ Hablando de su método científico, y del hallazgo del inconsciente, Freud expresa (1948b, p. 561): "No me hallaba influido por ningún sistema psicológico y que he ido formando y modificando mis opiniones hasta que me parecieron adaptarse perfectamente a lo observado". Añade con respecto a la formación de hipótesis teóricas: "No tengo a orgullo haber evitado la especulación, pero sí quiero hacer constar que el material en que se basan mis hipótesis han sido producto de una prolongada y laboriosa observación.”. Como es buen conocedor del empirismo, y sabiendo que rompe con una de sus prohibiciones, expresa: "Pero estoy seguro de que todo aquel que emprenda con igual método la investigación de tales fenómenos acabará por compartir mi actitud, a pesar de todas las advertencias de los filósofos".

2 Me refiero a escritos como: Freud (1914, vol. I), Metapsicología (1913-1917), El “yo" y el "ello" (1923) o Freud (1948, vol. II), Esquema del psicoanálisis (1910) o Introducción al psicoanálisis (1916-1918).
} 
Por otra parte, como bien lo sabe la concepción estructuralista -siguiendo en esto a Wittgenstein-, sin casos paradigmáticos no sabríamos cómo utilizar eso enunciados puramente teóricos, y que se encuentran desde su mismo comienzo inmersos en lo fáctico.

La formalización de ejemplares -y no de estructuras abstractas- que realizaremos parte de la convicción de que el conocimiento fáctico nunca podría ser caracterizado correctamente por estructuras vacías de contenido -como lo son los modelos matemáticos- y que incluso las estructuras matemáticas que pudieran emplearse se encuentran ya interpretadas. ${ }^{3}$

Como se mencionó anteriormente, esta estrategia introduce varias modificaciones a la reconstrucción estándar de las teorías. La primera consiste en reconstruir la teoría freudiana de la histeria utilizando los pasos del enunciado empírico ${ }^{4}$ como una forma más natural y pedagógica de hacerlo. Por otra parte, reconoce su importancia histórica, ya que el enunciado empírico de una teoría y sus problemas se encuentra en el origen del estructuralismo. La segunda modificación es utilizar diagramas para mostrar los elementos y relaciones de una teoría, en vez de la notación formal. Son más sencillos de comprender que los símbolos matemáticos y constituyen una manera diferente de exhibir la estructura de una teoría. Estos motivos pedagógicos e históricos pudieran ser suficientes para justificar la reconstrucción de la Teoría freudiana de la histeria mediante ejemplares y diagramas, y en este sentido, la comunidad estructuralista podría adoptarlos sin conflictos. Es más problemático que se acepte que con ellos se soluciona la tensión ontológica y epistemológica presente entre la coexistencia en el formalismo de un núcleo matemático sin interpretar, y un conjunto de aplicaciones empíricas como su semántica wittgensteiniana. Es una tensión -y quizás una contradicción- entre un núcleo platonista y el uso nominalista de la teoría. Esperamos que la reconstrucción que desarrollaremos más adelante sea considerada una solución adecuada de esa tensión, otorgándole una unidad nominalista.

En lo que sigue presentaré sucesivamente:

i. una síntesis del historial clínico de Dora,

ii. una reconstrucción de la teoría de la histeria de Freud, en una versión modificada de la concepción estructuralista;

iii. en el ínterin, argumentaré acerca de las consecuencias, para una ontología y teoría del conocimiento, de realzar una reconstrucción de ejemplares.

\section{Análisis fragmentario de una histeria}

Este es el título originario del texto de Freud, quizás más conocido como el Caso Dora. Presentaremos aquí una síntesis - por otra parte, incompleta- al solo efecto de brindar al lector una visión tanto de la historia misma, como de la manera en que procede Freud.

La paciente -a la que llama Dora- es una joven agraciada de 18 años, que es llevada a consulta por su padre, un hombre de unos 45 años, por presentar varios signos de enfermedad, que Freud inequívocamente atribuye a histeria, una entidad nosológica que la medicina del momento tenía bien estudiada y tipificada. Al igual que en medicina, llama signos a las alteraciones que presenta Dora, y que son los siguientes: tos nerviosa, ronquera, jaqueca, falsa apendicitis, depresión de ánimo, excitabilidad aumentada, aviso de suicidio dejando la carta a la vista, tedio vital.

Uno de los signos que según Freud permite identificar a la histeria, consiste en que el relato que hacen quienes padecen la enfermedad no es exacto ni coherente, y posee zonas oscuras, incluso amnesias y lagunas en los recuerdos.

\footnotetext{
${ }^{3}$ Usaré abstracto en dos sentidos. El primero refiere a entidades no espacio temporales. El otro refiere a estructuras lógicas o matemáticas no interpretadas. Trataré de mostrar que ambos son superfluos para la fundamentación del conocimiento fáctico. El primer sentido lo rechaza el nominalismo como pura metafísica platonista. Por supuesto, es necesario ser nominalista para decirlo. Además, trataré de argumentar -y presentar en la reconstrucción- que para reconstruir el conocimiento científico por medio de procedimientos lógicos o matemáticos, todo lo que se necesita es lógica y matemáticas interpretada, lo que evita la discusión acerca del carácter platónico de sus objetos.

${ }^{4}$ Ver más adelante sección 4.
} 
Para ese entonces, Freud (1896) había publicado en colaboración con J. Breuer los Estudios sobre la histeria en la que establece que en la génesis de la enfermedad existen hechos traumáticos y conflicto de afectos, en los que se encuentran involucrados aspectos de la sexualidad. Esos sucesos se ocultan reprimen-y por lo tanto se hacen patógenos. También había publicado el Análisis de los sueños, en el que sostiene que aparecen, transfigurados, en los sueños.

Hubo un episodio que narró Dora, y al que el padre, aun no creyendo que fuera verdadero, le atribuye la depresión de ánimo, la excitabilidad y sus ideas de suicidio.

El suceso que Dora les había comunicado a sus padres consistía en que en un paseo con el Sr. K, amigo de su padre, este le había hecho proposiciones amorosas. En principio, se trataba del hecho traumático característico de los Estudios sobre la histeria; pero el ulterior camino del análisis de Dora obliga a Freud a ir más allá de esta teoría primera; comenzando porque algunos de los signos habían aparecido mucho antes de este episodio, incluso a los ocho años. Algo que lo hace buscar más atrás en el tiempo. Hubo, en efecto, un beso forzado por K cuando Dora tenía 14 años, y que le provoca una sensación de repugnancia, un suceso que había olvidado, al igual que los que pudieron estar relacionados con sus signos de la infancia.

Freud concluye que para ese entonces ya estaba histérica, puesto que, al estar enamorada de K, lo normal habría sido sentir alguna excitación genital, pero no repugnancia. Cree que advirtió el pene erecto de K, y que esta sensación la desplazó hacia arriba, hacia el aparato respiratorio, provocando tos y ronquera, así como repugnancia y nausea.

Ante la indiferencia de la familia de Dora, $\mathrm{K}$, que era muchos años mayor, le llevaba flores todos los días, y le hacía regalos importantes.

Dora piensa que su padre, que era amante de la mujer de $\mathrm{K}$, lo consiente para que no inoportune esta relación; en cierto sentido, la entrega a $\mathrm{K}$.

Freud cree que debió haber episodios traumáticos aun antes, pues presentaba síntomas incluso a los 8 años, y que, como veremos luego, fueron revelados durante el análisis del primer sueño.

Freud enuncia la regla de que el síntoma representa la realización de una fantasía de origen sexual.

Su ejemplificación sigue un largo camino que relataremos a continuación. Comienza cuando Dora expresa que su padre es un hombre de recursos (monetarios), a lo que Freud acota que -haciendo una inversión del sentido-, en realidad piensa que tiene recursos limitados, otra forma de manifestar que es impotente; algo que no es contradictorio con las relaciones que mantiene con la señora $\mathrm{K}$, pues ella Dora- sospecha que se satisfacen de otra manera, mediante sexo oral. Este el origen probable de los signos que experimenta en su boca y garganta.

El que desapareciera la tos con esta explicación confirma la validez de la interpretación.

Para aquellos que creen que una joven no puede tener estos pensamientos y conocimientos, Freud aduce que las perversiones tienen su origen natural en la sexualidad primaria, y que todos pueden pasar el límite de lo normal, aunque habitualmente se sublima -i.e. es energía que se usa para otros fines- y lleva a producir la cultura. Freud imagina que por asociación de imágenes, es sencillo pasar de la sensación erótica en los labios durante la succión del pecho en el infante -sexualidad primaria-, al pene, haciendo un camino intermedio que pasa por la visión de bebés desnudos, y de terneros mamando de su madre.

Freud ya había esbozado su teoría del enamoramiento temprano del padre -complejo de Edipo-, que fija el impulso amoroso que en la pubertad toma la forma de inclinación sexual.

Nos relata que Dora cuidaba a su padre durante sus períodos de enfermedad (una tuberculosis pulmonar que lo obligó a vivir en lugares especiales, donde conoció a K y su mujer). Celaba al padre, pero también sentía celos homosexuales por la mujer de K. Dora manifiesta una idea predominante, obsesiva, acerca de las relaciones ilícitas de su padre con la señora $\mathrm{K}$, pero al mismo tiempo reprime su amor hacia $\mathrm{K}$, y encubre el que siente por su mujer, en procesos que son totalmente inconscientes. Freud acota que cuando la libido sexual de las histéricas orientada hacia el hombre queda reprimida, aparece intensificada la corriente homosexual, que llega a ser incluso consciente. Pueden coexistir ideas contradictorias, como el amor hacia $\mathrm{K}$, y hacia su mujer, que lo criticaba tanto. 
Dora relata dos sueños durante su tratamiento. Narraremos sólo el primero. Es altamente sintomático de las interpretaciones freudianas.

El primer sueño [...]. Dora lo describió en la forma siguiente: «Hay fuego en casa. Mi padre ha acudido a mi alcoba a despertarme y está en pie al lado de mi cama. Me visto a toda prisa. Mamá quiere poner aún en salvo el cofrecito de sus joyas. Pero papá protesta: 'No quiero que por causa de tu cofrecito ardamos los chicos y yo.' Bajamos corriendo. Al salir a la calle, despierto.» (Freud 1948b, p. 537)

Como sucede en ocasiones, existen sucesos que ocurren en la vigilia y con cuyos materiales se construye el sueño. Son los siguientes: La madre deja cerrado el comedor, y con eso también la salida del dormitorio del hermano. El padre llega en medio de una tormenta a la localidad en la que se encontraba la familia, y expresa el temor de que los rayos pudieran provocar un incendio en la cabaña de madera en la que veraneaban.

Algunos de los elementos que aparecen en el sueño, como el fuego, el dormitorio cerrado que podría dañar a los hijos, la actitud protectora del padre, ya están allí, en los acontecimientos de ese día.

Cuando Freud profundiza en el sueño, Dora relata que lo tiene después del suceso en que $\mathrm{K}$ pretende besarla: por lo tanto, es una respuesta al mismo. Recuerda que K estuvo cerca de ella cuando dormía en su alcoba; por eso quiere cerrarla con llave, pero la llave no está en su lugar (piensa que K la sacó). Por eso se viste siempre con prisa (como dice en el sueño). Eso duró cuatro noches, las que estuvieron en el sitio de veraneo.

Aquí el sueño pasa de un suceso diurno obvio, a otro de la intimidad de Dora. Freud ya había establecido anteriormente que el sueño es la representación de deseos. Al profundizar, surge nuevo material que reinterpreta al sueño, y que conduce a otros hallazgos del pasado de Dora.

$\mathrm{K}$ le había regalado un cofrecito. Es una figura que hace alusión al genital femenino. Mi cofrecito mi sexo- corre peligro, dice el sueño. La salva el padre. La madre aparece en él -aunque no se encontraba en la cabaña de veraneo-, pues Dora está dispuesta a dar a su padre lo que la madre le niega (el cofrecito) -antes había manifestado que creía que sus padres no tenían relaciones sexuales-. La figura femenina de la madre puede sustituir a la señora $K$, quien finge estar enferma para no tener relaciones con su esposo; si esto es así, en el sueño Dora expresa ahora con respecto a $\mathrm{K}$-en esa ambivalencia de los sueños-, que puede darle lo que su mujer le niega. Dora, interpreta Freud, teme ceder a sus deseos por $\mathrm{K}$.

Aquí aparece por primera vez en la interpretación lo infantil: un sueño tiene como origen un suceso actual y uno infantil. El deseo que satisface -el Edipo- es infantil.

Mientras hablan del sueño, Dora pone una caja de fósforos sobre la mesa. Freud asocia fósforos con jugar con fuego, e inmediatamente con orinarse (un viejo dicho expresa que quien juega con fuego se orina). Dora recuerda -habiéndolo olvidado hasta ese momento- que tuvo enuresis hasta los 8 años. Su causa siempre -en el conocimiento de Freud de esa época- es la masturbación, que Dora confiesa, y que en el sentido común de la época, provoca asimismo flujo genital -leucorrea-. Sabe que el padre tuvo enfermedades venéreas, que sospecha contagió a la madre, puesto debió tratarse de flujo debido supuestamente a esta causa. Cuando Freud se lo dice, juega con un bolsillo de piel que abre y cierra, y al que introduce su dedo, un acto sintomático con el que reconoce lo acertado de la interpretación.

En la extensa interpretación del sueño, surgen recuerdos reprimidos que tienen que ver con los episodios de histeria de Dora a los 8 años, a los 14, y antes del tratamiento.

La disnea, el asma, esos signos de su histeria, provienen de imitar el resoplido de su padre durante el coito, un recuerdo que había reprimido. Una imitación similar es la causa de su catarro, que es parecido a la tos del padre.

El deseo de reemplazar a K por su padre es lo que proporciona la energía que causa el sueño.

El olor a humo que recuerda del sueño tiene que ver con el aliento a tabaco de $\mathrm{K}$ cuando la besó.

Dejamos aquí las evoluciones de la compleja vida afectiva de Dora; su amor por K, a quien rechaza, la atracción que siente por su mujer, la reproducción en esas relaciones de su afecto infantil por su 
padre -su Edipo-, así como las relaciones primeras con una institutriz, el segundo sueño, y las escenas de terminación del tratamiento por parte de Dora.

Freud, quien sabe que los lapsos temporales son importantes para Dora, le muestra que cuando le comunica que después de quince días pondría fin al tratamiento, ese plazo coincide con el del preaviso de despido del personal doméstico, y que se relaciona -entre otras circunstancias- con el despido de una mucama que sucumbe a la seducción de su padre, y que le es comunicado con 15 días de antelación.

Sin profundizar en estas escenas finales, diremos son el vehículo para que Freud haga conocer al lector la noción de transferencia, mostrando que Dora proyecta sobre él experiencias anteriores.

Pero dejemos ahora la historia de Freud y Dora, para reconstruirla utilizando nociones centrales de la concepción estructuralista de las teorías. ${ }^{5}$

En lo que sigue, presentaremos las nociones principales de la concepción estructuralista. Luego argumentaré, desde el interior de esa concepción, acerca de la utilización del enunciado empírico como una estrategia para reconstruir las teorías, en vez de la manera más usual de caracterizarla por sus modelos matemáticos. De acuerdo con el enunciado empírico, y siguiendo sus etapas, propondremos una reconstrucción de la Teoría freudiana de la histeria que conserva las características centrales del estructuralismo, sin recurrir a estructuras formales/matemáticas.

\section{La concepción estructuralista}

Recordemos que para la concepción estructuralista la mejor manera de caracterizar a una teoría es especificando la clase de sus modelos, a las que un conjunto de aplicaciones brinda una interpretación empírica.

Para quienes no estén familiarizados con la empresa estructuralista o con su jerga, diremos que una teoría - T- se caracteriza mediante un núcleo abstracto -K-, y un conjunto de aplicaciones propuestas -I- de este núcleo:

$$
\mathrm{T}=\langle\mathrm{K}, \mathrm{I}\rangle \text {. }
$$

A su vez, el núcleo abstracto $\mathrm{K}$ se encuentra integrado por varios tipos de modelos, según se encuentren caracterizados por las funciones no teóricas de la teoría, por éstas más las funciones teóricas o si además cumplen un axioma legaliforme que relaciona entre sí a objetos y funciones de la teoría, de tal manera que:

$$
\mathrm{K}=\left\langle\mathrm{M}_{\mathrm{p}}, \mathrm{M}, \mathrm{M}_{\mathrm{pp}}, \mathrm{C}, \mathrm{L}\right\rangle .
$$

Los modelos que poseen tanto las funciones teóricas como las no teóricas son los modelos potenciales $\mathbf{M}_{\mathrm{p}^{-}}$. Los modelos caracterizados por las funciones no teóricas se denominan modelos parciales $-\mathbf{M}_{\mathbf{p p}}{ }^{-}$. Finalmente, aquellos que cumplen por añadidura un axioma relacional, se denominan modelos - $\mathbf{M}-$.

Como vemos, hemos añadido a los modelos una relación $\mathrm{C}$ que existe entre los distintos modelos de la teoría, y una relación $\mathbf{L}$ entre esos modelos y otros de otras teorías.

Es necesario especificar que la concepción estructuralista distingue entre términos no-teóricos como aquellos que provienen de otra teoría, y términos teóricos, que son propios de la teoría en cuestión. Es una distinción relativa a la teoría reconstruida, puesto que un término no-teórico en una teoría dada la de Freud, en este caso- puede ser teórico en otra. Se afirma la teoricidad de una función cuando sólo puede ser determinada en una aplicación exitosa de la teoría, es decir, funciona como tal en un sistema en el que la teoría se aplica a pleno.

Es entonces, una distinción relativa a una teoría -una función es T-teórica o T-no-teórica en la teoría T- y funcional, según el rol que juega en la teoría en cuestión.

\footnotetext{
${ }^{5}$ Dora es el pseudónimo con el que Freud nombra a Ida Bauer, hermana de Otto Bauer, el gran dirigente austromarxista, a su vez relacionado con Otto Neurath, autor del Manifiesto del Círculo de Viena junto con Rudolf Carnap y Hans Hahn.
} 
Difiere de la distinción tradicional entre términos teóricos y observacionales puesto que esta última es epistemológica -se refiere a la observabilidad o no de objetos y propiedades- y absoluta, puesto que algo será observable o no cualquiera sea la teoría que se considere.

Las aplicaciones propuestas I integran un conjunto abierto de sistemas fácticos propuestos como ejemplares de la teoría, y que funciona a la manera de semántica informal à la Wittgenstein, dándole contenido empírico a los modelos abstractos de $\mathrm{K}$.

En la caracterización habitual de la concepción estructuralista, los sistemas que forman parte de I son un subconjunto de los modelos parciales $\mathbf{M}_{\mathrm{pp}}$.

Si procediéramos a realizar una reconstrucción siguiendo las normas habituales, tendríamos que caracterizar primeramente a los modelos potenciales $-\mathbf{M}_{\mathbf{p}}-$, introducir sobre ellos un recorte de los términos teóricos que nos permita identificar a los modelos parciales $-\mathbf{M}_{\mathrm{pp}^{-}}$, y finalmente, establecer, con los axiomas legaliformes, los modelos actuales $\mathrm{M}$ de la teoría.

Luego, las aplicaciones se identifican formalmente como un subconjunto de los modelos parciales.

Por supuesto, este enfoque participa -junto con otras concepciones, incluida la "heredada"- de la percepción de las teorías científicas como cálculos sin interpretar; entidades abstractas, desde el punto de vista ontológico. Difiere de otras, sin embargo, en que se incluye, junto con el aparato matemático, a un elemento pragmático, las aplicaciones propuestas, como forma de darle contenido empírico.

\section{El enunciado empírico como estrategia de reconstrucción}

Alejándonos de concebir a las teorías científicas como entidades abstractas -no las hay, desde el punto de vista nominalista-, o estructuras matemáticas vacías -es imposible que en algún momento se pierda el contenido empírico con el que se las construye-, nuestra reconstrucción de la teoría freudiana de la histeria se asienta en lo que quizás fue el inicio de la concepción estructuralista, a saber, la manera de hacer una afirmación empírica, sabiendo que en el aparato conceptual de cualquier teoría existen términos teóricos.

Joseph Sneed (1971) en el texto fundacional de la concepción estructuralista, sostiene que no se puede hacer directamente un enunciado empírico en lenguaje conjuntista de la forma " $a$ es un S", siendo a un sistema físico y $S$ una teoría. Hacerlo implicaría -dada la presencia de los términos teóricos- que la teoría sería autoconfirmatoria. Propone como solución que primeramente se enuncie que un sistema físico descripto mediante sus funciones no teóricas, puede ser expandido añadiéndole las funciones teóricas, y finalmente, que satisfarán asimismo las leyes de la teoría. No nos extenderemos más en el asunto, pero diremos que se trata de una modificación de la eliminación-Ramsey de los términos teóricos.

Lo que hace sumamente interesante a esta propuesta a los ojos del científico, es que según la concepción estructuralista, esta es una reconstrucción de cómo se utiliza efectivamente una teoría, y por consiguiente, que constituye una elucidación de la práctica científica. En efecto. Según la concepción estructuralista, cuando los científicos investigan, siguen sucesivamente cada uno de estos pasos. En síntesis, como lo hiciera notar Stegmüller, se trata de una afirmación empírica acerca del comportamiento de los científicos, que no ha sido refutada hasta el momento.

Si los análisis que realizamos hasta ahora son correctos, la afirmación empírica no sólo constituye una reconstrucción del uso de una teoría, sino también la elucidación de los pasos de su construcción durante su génesis.

En concordancia con la afirmación empírica, conservamos dos distinciones en nuestra reconstrucción. La primera es la que diferencia entre términos teóricos y no-teóricos. La segunda, la que distingue entre las diferentes estructuras -parciales, potenciales, actuales- que se explicitan utilizándolos. Con ellas estableceremos los rasgos estructurales con los que Freud describe a Dora, para que sea una histérica psicoanalítica.

En nuestra propuesta no nos separamos nunca del nivel ontológico de los ejemplares - de los casos individuales-, ni por supuesto, del elemento pragmático de un individuo -Freud o alguno de sus 
discípulos- que siguiendo los pasos especificados hace la aserción empírica de que Dora -u otro paciente cualquiera- es un caso más de histeria psicoanalitica.

Tampoco abandonamos ese elemento wittgensteiniano por el cual un practicante del psicoanálisis encuentra parecidos entre este caso paradigmático y otro, tal que lo autorice a hacer algunas investigaciones que le permitan incluirlo en la teoría.

\section{Hacia una reconstrucción de ejemplares}

Llegados a este punto, es necesario remarcar que intentamos conferir un rol central al enunciado empírico del estructuralismo, conservando sus distinciones y sus etapas constructivas para reconstruir la Teoría freudiana de la histeria a partir de sus ejemplares -es decir, de los casos de histeria que analiza- y en particular, de su caso paradigmático. Esta perspectiva puede ser llamada nominalista.

$\mathrm{Al}$ hacerlo, mostraremos un ejemplar paradigmático de estructuralismo sin entidades abstractas, un camino a seguir para quienes piensen que el platonismo es una doctrina con serios problemas epistemológicos -no posee una teoría plausible del conocimiento- y postula entidades fantásticas, trabando preguntas que son legítimas desde la neurofisiología, cuyo programa de investigación se fundamenta precisamente en sentar las bases de una explicación orgánica de la conducta y de los fenómenos psicológico, como bien lo supo hace más de un siglo el neurofisiólogo Freud.

Si se efectúa una reconstrucción de los ejemplares de la teoría, nunca se deja de tener en cuenta que aunque se adopte en la exposición formas más generales, se está hablando siempre de Dora, y, en consecuencia, de todos los pacientes que presentan características similares a las de Dora.

Mostraremos que no es necesario -ni siquiera deseable- reconstruir la teoría comenzando por modelos matemáticos, que conllevan el peligro -como efectivamente sucede- de sostener que son empíricamente vacíos, y que por lo tanto necesitan interpretación. Si se lo hace, se recae innecesariamente en un platonismo ontológico, ocultándose que en su génesis la teoría nunca dejó de tener contenido empírico, y que siempre se procedió desde formas más cercanas a la experiencia, a formas más generales.

Por ese motivo, comenzaremos nuestra reconstrucción por los ejemplares parciales $-\mathrm{I}_{\mathrm{pp}}-$ que son funcionalmente equivalentes a los modelos parciales $-\mathbf{M}_{\mathrm{pp}}-$ de las reconstrucciones habituales del estructuralismo, y que se caracterizan por poseer únicamente funciones no-teóricas. Seguiremos luego por los ejemplares potenciales $-\mathbf{I}_{\mathbf{p}}$ - de la teoría, equivalentes a los modelos potenciales $-\mathbf{M}_{\mathbf{p}}-$, que resultan de añadirles las funciones teóricas. Y finalmente I, los ejemplares actuales que se corresponden con los modelos actuales - M- de la teoría, que satisfacen además uno o más axiomas legaliformes que relacionan entre sí a objetos y funciones.

Es necesario remarcar que al hacerlo así, se modifica la versión estándar del enunciado empírico, que comienza por aplicaciones parciales que al ser enriquecidas por funciones teóricas pasan a ser modelos potenciales. Esta secuencia implica un salto ontológico y lingüístico injustificado. Es imposible que la adición de funciones teóricas transforme una aplicación empírica -un ejemplar- en una estructura matemática abstracta, o a un lenguaje interpretado en un lenguaje matemático puro, no interpretado.

En este sentido, la reconstrucción de la teoría mediante sus ejemplares es nominalista -empleamos nominalista en el sentido que refiere a entidades espacio-temporales, y por lo tanto, prescinde de entidades abstractas- ${ }^{6}$

Pero entonces, ¿qué sucede con las entidades psicológicas de la teoría de Freud, e incluso con el conocimiento que elabora mientras avanza el tratamiento de Dora -o incluso nuestro conocimiento de los escritos de Freud o de la filosofía de la ciencia-? ¿Son sucesos mentales, inmateriales, abstractos?

Nuestra respuesta es que los sucesos psicológicos son básicamente la expresión de fenómenos neurofisiológicos, como lo señala Freud, de quien no nos apartamos demasiado en estos asuntos.

\footnotetext{
${ }^{6}$ Al decir de Goodman y Quine (1947), el nominalismo consiste -entre otras características- en negar la existencia de entidades abstractas.
} 
Mucho más temprano, en Proyecto de psicología para neurólogos, ${ }^{7}$ Freud propone una fundamentación neurológica para el aparato psíquico. En el Caso Dora insiste en que "[s]ólo la técnica terapéutica es puramente psicológica. La teoría no omite señalar la base orgánica de la neurosis, aunque no la busque en una alteración anatomopatológica, y sustituya provisoriamente la supuesta alteración química, inaprehensible aún, por la interinidad de la función orgánica”. Remarca asimismo que nadie puede negar el carácter orgánico de la función sexual, que se encuentran en las bases de la histeria y de las psiconeurosis en general.

En síntesis, y más formalmente, la teoría freudiana de la histeria se caracteriza por la identificación de tres instancias en sus ejemplares parciales, potenciales, actuales:

$$
\mathrm{TFH}=\left\langle\mathrm{I}_{\mathrm{pp}}, \mathrm{I}_{\mathrm{p}}, \mathrm{I}\right\rangle .
$$

Seguimos utilizando la letra I para designar a los ejemplares de la teoría, puesto que para la concepción estructuralista las aplicaciones -que designa con la letra I- son ejemplares que la comunidad científica acepta como tales en un punto determinado del desarrollo histórico de la teoría, de manera similar a lo que se expondrá en adelante.

Luego veremos que a estas tres instancias es necesario añadirles unos presupuestos que actúan como las condiciones de ligadura - C- de la concepción estructuralista, y que conectan entre sí a los distintos ejemplares de la teoría. Además, el cuadro se completa si especificamos las relaciones que guarda esta teoría con otras -relaciones interteóricas-, que denotamos con la letra L, tal que:

\section{$\mathrm{TFH}=\left\langle\mathrm{I}_{\mathrm{pp}}, \mathrm{I}_{\mathrm{p}}, \mathrm{I}, \mathrm{C}, \mathrm{L}\right\rangle$.}

\subsection{Los ejemplares parciales de $\mathbf{I}_{\mathrm{pp}}$ de la histeria}

Habíamos mencionado que en los ejemplares parciales $I_{\mathrm{pp}}$ de la histeria, aquello que es no-teórico, provienen generalmente de teorías anteriores, y constituyen su base de contrastación, lo que debe explicar.

En el caso de la teoría freudiana de la histeria, consideramos que lo no-teórico proviene de la psiquiatría de la época, que ya había caracterizado e identificado a la histeria, y de la psicología de la época, para la cual el concepto de representación ${ }^{8}$ era de uso habitual.

Estas son las teorias de base que subyacen a la concepción de Freud sobre la histeria. Sabemos que cuando Freud comienza a estudiar la histeria junto a Breuer, ya había estudiado con Charcot la psiquiatría y neurología más avanzada de su época, y particularmente a una enfermedad clave para la especialidad, la histeria. ${ }^{9}$ También había concluido su etapa de investigaciones neurofisiológicas, en las que tanto se destacó -al punto que su nombre quedó incorporado para siempre al estudio de las afasias-, y que lo marcaron tanto que nunca renunció a que la enfermedad psicológica -y por ende sus propias construcciones teóricas- tuvieran una base orgánica en el sistema nervioso central.

Comencemos pues con nuestra caracterización informal de los ejemplares parciales $-\mathrm{I}_{\mathrm{pp}}-$ de la Teoría freudiana de la histeria.

\footnotetext{
${ }^{7}$ Se trata de un manuscrito de Freud de 1895 conservado por su amigo Wilhelm Fliess, cuya existencia se conoce recién en 1950, y que fue publicado en el primer tomo de la Standard Edition a cargo de J. Strachey hacia 1955. De su importancia da cuenta Strachey cuando escribe (Freud, Obras completas, vol. I, p. 333): “[...] en verdad, el Proyecto, o más bien su fantasma invisible, está calladamente presente en toda la serie de los escritos teóricos de Freud, hasta el final”. Añadamos que numerosos autores de nuestros días lo consideran un texto fundamental para la neuropsicología y la teoría cognitiva actuales. Permaneció sin publicar muchos años, y fue recogido por la edición inglesa. El original no poseía ningún título. Ver "Project for a Scientific Psychology", en Freud (2000), Pre-Psycho-Analytic Publications and Unpublished Draft, vol. I (1886-1899), pp. 283-294.

${ }^{8}$ La noción de representación proviene en la tradición alemana de Kant, y era utilizada por las diversas corrientes filosóficas, psicológicas y epistemológicas de la Viena de la época de Freud, particularmente Hermann von Helmholtz, Ernst Mach, Heinrich Hertz o Ludwig Wittgenstein. Las palabras alemanas utilizadas eran Bild, literalmente imagen o diseño, y traducido a menudo como pintura, y más específicamente Vorstellungen, un equivalente de la idea de los filósofos empiristas ingleses, como representación de sensaciones, y en cierto sentido privada, o Darstellungen, utilizado en un sentido más público, lingüístico.

9 Freud, S. (1893), "Quelques considérations pour une étude comparative des paralysies motrices organiques et hystériques", Archives de Neurologie 26(77): 29-43. "Charcot, cuyo alumno fui en 1885 y 1886, me confió en esta época la labor de realizar un estudio comparativo de las parálisis motrices orgánicas e histéricas, basado en las observaciones efectuadas en la Salpêtrière y encaminado a descubrir algunos caracteres generales de la neurosis y a conducirnos a una concepción de la naturaleza de tal enfermedad" (pp. 29-30).
} 
Lo haremos mediante un diagrama en el que se indican cuáles son los elementos no-teóricos de los que habla la teoría, y las relaciones que entablan en esta etapa de su caracterización. Como regla general de nuestros diagramas, mostraremos a los primeros mediante círculos, y a las relaciones con las líneas que los unen. ${ }^{10}$

Los motivos para preferir esta manera de exponer la estructura de una teoría son, por un lado, el facilitar la captación de sus núcleos centrales a quienes no están muy familiarizados con los simbolismos de la teoría de conjuntos y de modelos.

Pero, por otro lado, se debe a que al renunciar a la notación habitual del estructuralismo, indicamos fuertemente que no se trata de modelos abstractos, sino de ejemplares empíricos.

Por supuesto, esta manera de exhibir la estructura de la teoría podría reemplazarse -si así se quisiera- por una notación que permaneciera, como es usual, dentro de los límites de la teoría de conjuntos y de modelos, a la que se les podría dar una interpretación nominalista -por ejemplo, considerarla sólo signos que son leídos por un sujeto epistémico entrenado-. Si así se hiciera, se trataría, en síntesis, de la utilización por razones pragmáticas de un lenguaje determinado, que permite hablar de elementos y relaciones que sólo pueden ser expresados en él.

De hecho, se sostiene que la descripción de la teoría realizada mediante diagramas puede transcribirse a dicho lenguaje sin que exista pérdida alguna en el proceso -siempre que se reconstruya como ejemplares, y no como modelos abstractos que necesitan interpretación-.

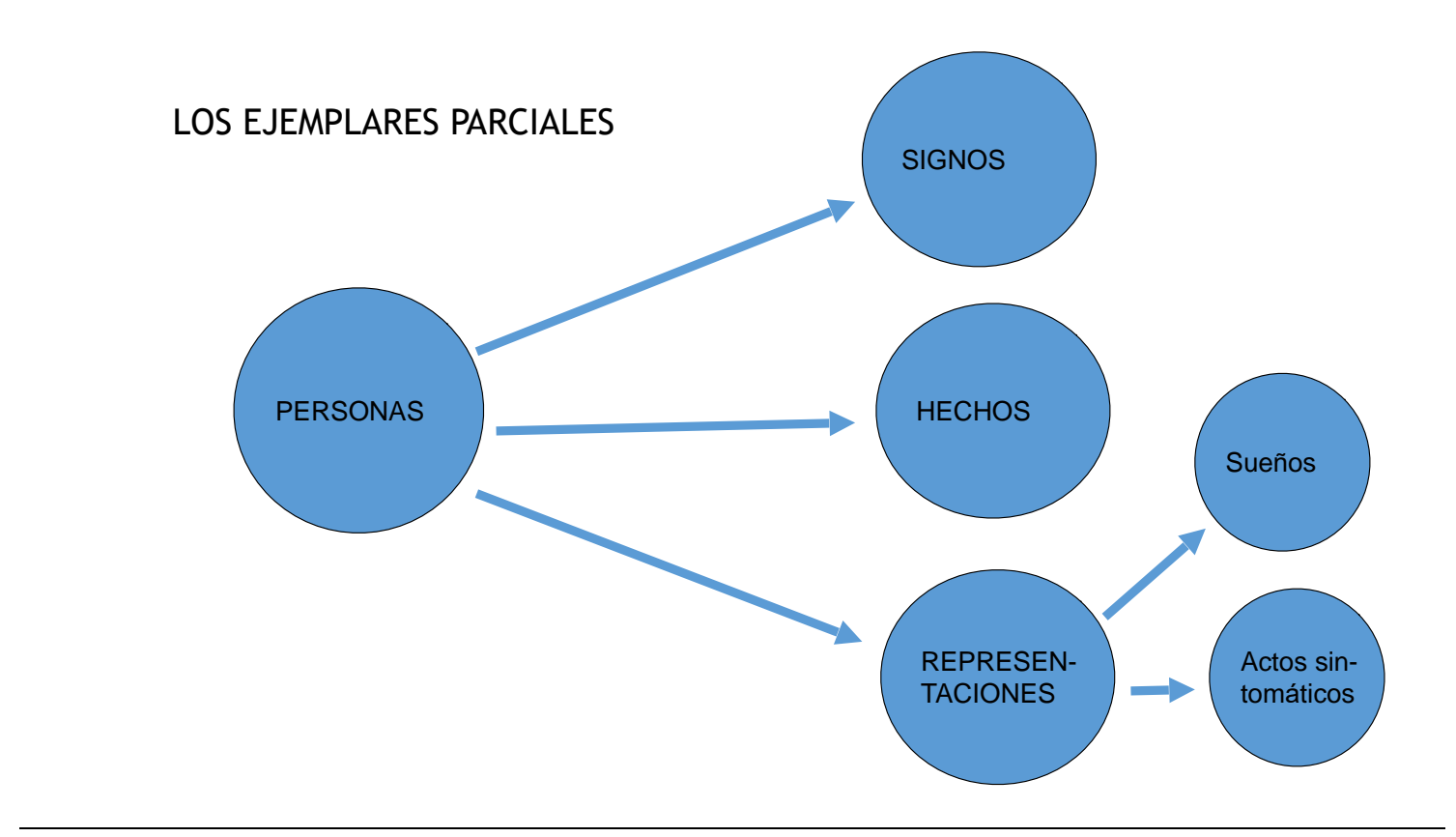

En este esquema, los objetos de la teoría -aquello de lo que habla, su ontología- son Personas, seres humanos.

En la historia clínica de Dora, no aparecen demasiados: la misma Dora, su padre, el señor K, la esposa de K, Freud; se mencionan apenas otros personajes del drama que representa la histeria de Dora.

Si profundizamos en otras historias clínicas, y en las exposiciones teóricas de Freud, habitualmente se trata de relaciones interpersonales con escasos personajes,

Los elementos no-teóricos que afectan a las personas son, como vemos:

i. Signos somáticos y psíquicos, es decir, las manifestaciones de la histeria que presenta Dora, y que fueron caracterizadas según lo plantea la psiquiatría de la época, como las que se mencionaron anteriormente.

\footnotetext{
${ }^{10}$ Consideramos que un sistema es una estructura integrada por objetos y relaciones.
} 
ii. Hechos -como sucesos interpersonales en los que interviene Dora-, y finalmente

iii. Representaciones de esos Hechos.

Las relaciones entre hechos y representaciones se encuentran esquematizadas en el diagrama por una línea que los une, así como también se advierten las relaciones entre personas, y signos, hechos y representaciones.

Cabe mencionar que para Freud las representaciones -huellas mnémicas de los hechos- son fundamentalmente imágenes, ${ }^{11}$ aunque integran una Gestalt compleja de la que no faltan registros olfativos, táctiles o gustativos.

Debemos añadir a estos elementos no-teóricos ya conocidos por lo médicos y psicólogos, dos elementos que no se suponía que tuvieran ninguna relación con la histeria.

Ellos son:

iv. Sueños y

v. Actos sintomáticos.

El primero de estos elementos fue estudiado por Freud en su Interpretación de los sueños, un texto en el que establece su importancia para la exploración del inconsciente. Los actos sintomáticos, tales como tics, jugar con monedas en el bolsillo, perder objetos, también fueron estudiados por Freud en su significado inconsciente antes del Caso Dora:

Le doy el nombre de actos sintomáticos a esos actos que se hacen, diríamos, automáticamente, inconscientemente, sin prestarles atención, como si fuera en un momento de distracción. Esos actos a los que la gente gustaría negarles toda importancia, y si se les pregunta, ellos dirían que son indiferentes o casuales. (Freud 1948b, p. 543)

Es interesante notar que en este sentido Freud continúa la tradición médica de reinterpretar y poner en un contexto semiológico elementos que provienen del conocimiento común. No se los incluye entre los Signos de la histeria porque no puede diagnosticársela basándose en sueños o tics de los pacientes. Son elementos no-teóricos que Freud usa para explorar el inconsciente de los pacientes mediante las herramientas de la interpretación psicoanalítica. En el sentido común, se relacionan con otro elemento no-teórico, las representaciones. Veremos más adelante que son también la exteriorización de las representaciones reprimidas de la histeria.

\subsection{Los ejemplares $\mathbf{I}_{\mathbf{p}}$ de la histeria}

A fin de obtener los ejemplares potenciales de la teoría, añadimos los elementos teóricos a los ejemplares parciales.

Es necesario recordar, sintetizando la exposición de Freud del Caso Dora, que la sexualidad tiene un rol primordial en la génesis de la histeria, al punto de llevarlo a sostener que en se encuentra involucrada en todos los aspectos de la enfermedad.

\footnotetext{
${ }^{11}$ Así lo presenta en La interpretación de los sueños. Aunque hay en este texto reflexiones no sólo acerca de imágenes y cómo se relacionan una con otra, sino también cómo las palabras dan lugar a asociaciones simbólicas, estos mecanismos actúan principalmente a partir de la forma escrita que poseen, como si fueran sólo una imagen más de las que pueblan los sueños.
} 


\section{LOS EJEMPLARES POTENCIALES I}

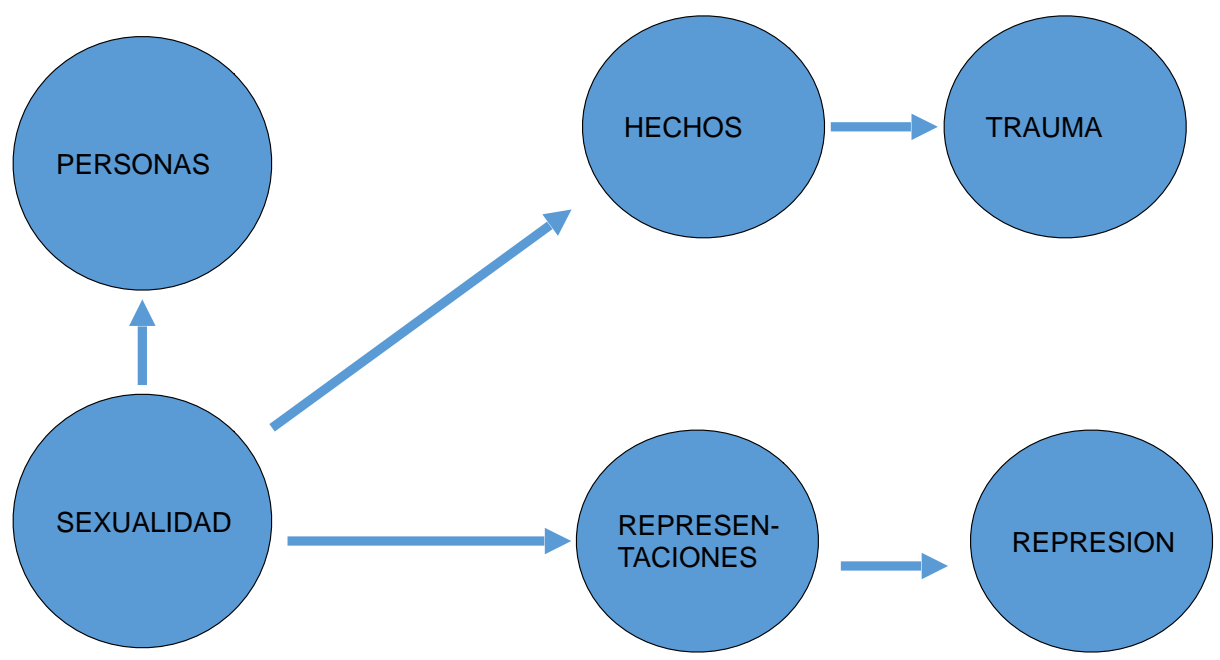

\section{LOS EJEMPLARES POTENCIALES II}

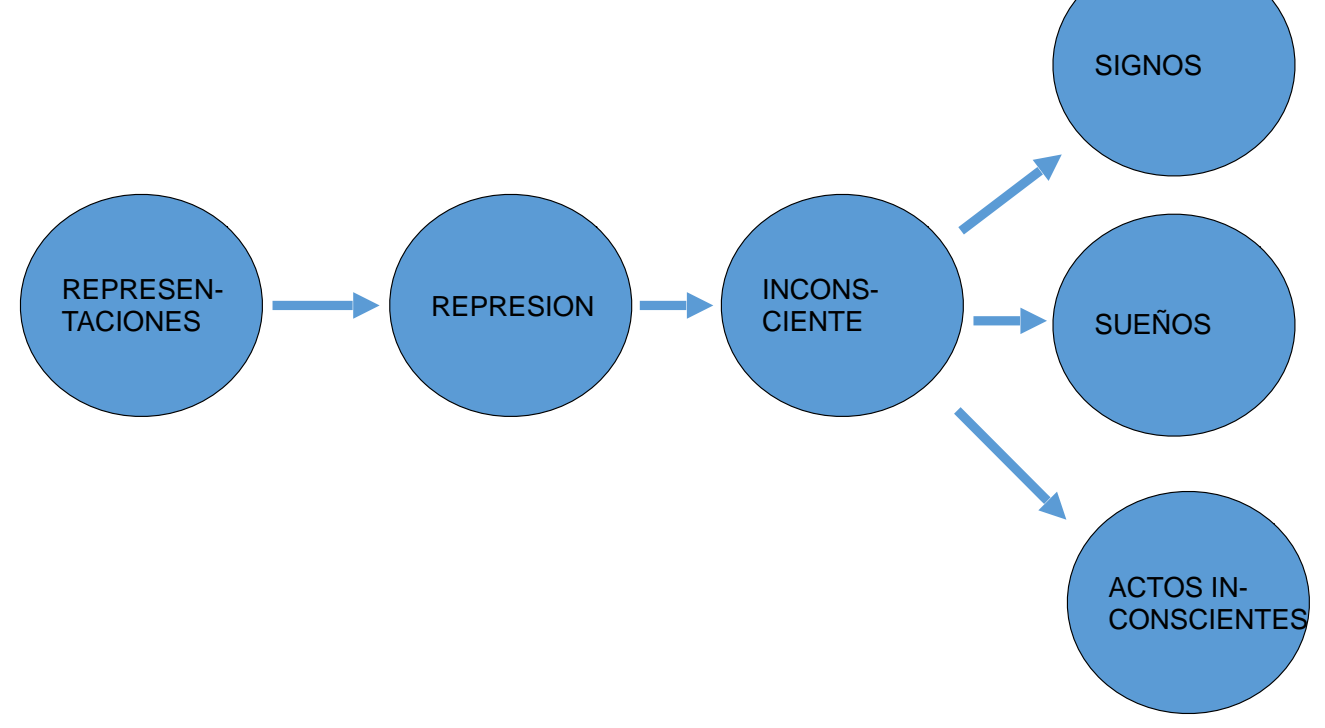

Nuestro diagrama reproduce el de los ejemplares parciales $-\mathbf{I}_{\mathrm{pp}^{-}}$, añadiéndole los elementos que introduce la teoría. A fin de facilitar su comprensión, estos elementos nuevos tienen color rojo.

Ellos son:

i. Sexualidad. Para Freud, en todos los aspectos de la histeria se encuentran involucrados aspectos sexuales. En rigor, actúa sobre los tres aspectos no teóricos que vimos anteriormente. Posee dos formas de manifestarse, hetero y homosexual. ${ }^{12}$

ii. Trauma. Los aspectos sexuales de un hecho vivido por los pacientes hace que éste se transfigure en un trauma.

iii. Represión. La acción de la sexualidad sobre la representación del hecho traumático hace que ésta se reprima, y entonces:

\footnotetext{
${ }^{12}$ Freud introduce por primera vez el término libido en "La neurastenia y la neurosis de angustia ( $\left.{ }^{\star} 27\right)$ - Sobre la justificación de separar de la neurastenia cierto complejo de síntomas a título de "neurosis de angustia»" - 1894 [1895] nota 30, para referirse a la excitación sexual que se transforma en estímulo psíquico. Distingue así entre lo estrictamente somático -sexualidad- de lo psíquico -libido- de la tendencia sexual. Curiosamente, en el escrito sobre Dora utiliza exclusivamente el término sexualidad.
} 
iv. deviene Inconsciente para el sujeto.

v. Una relación E -exteriorización- conecta a Inconsciente con Sueños, Actos sintomáticos y Signos.

Tenemos ya explicitados los elementos teóricos de la teoría de la histeria. En el diagrama, de la Sexualidad salen líneas que la conectan con los tres elementos no-teóricos.

Ya hemos mencionado que actúa sobre los hechos, y sobre la representación, y esto está mostrado por las líneas que llevan de Sexualidad a Hechos y a Representación.

Es necesario añadir que actúan también sobre los signos, ya que según Freud, éstos, una vez llegados a su total desarrollo, representan una situación fantaseada de la vida sexual, es decir, una escena del comercio sexual, un embarazo, el puerperio, etc. Como se muestra por la línea que une a Sexualidad y Signos.

Las representaciones inconscientes se exteriorizan mediante E, en forma de Actos Sintomáticos, Signos, Sueños.

Freud tiende a pensar que las representaciones, como mecanismos generales de la psiquis, se exteriorizan como recuerdos, o se olvidan sin ningún síntoma. Es únicamente cuando presentan un carácter sexual traumático que se exteriorizan por caminos oblicuos -sueños, actos simbólicos- y no se olvidan ni se conocen como recuerdos.

\subsection{Los ejemplares actuales I}

Los ejemplares actuales I poseen además de los elementos teóricos y no teóricos, axiomas en forma de ley que cumplen la función de relacionarlos entre sí.

En el caso de la teoría freudiana de la histeria, estas leyes generales dicen lo siguiente:

\section{Axioma 1:}

Para cualquier caso de la teoría freudiana de la histeria, existen hechos a los que la sexualidad -homo o heterosexuales- los hace traumáticos y que provoca que sus representaciones se repriman, y se vuelvan inconscientes, exteriorizándose como síntomas histéricos, sueños y actos sintomáticos.

Este axioma surge de simplificar los hallazgos freudianos del caso Dora, eliminando sus peculiaridades, y generalizándolos a los efectos de suponer, hipotéticamente, que son aplicables en otros casos similares.

Existe un axioma adicional que expresa que cualquier caso de la teoría freudiana de la histeria es similar al caso de Dora, su caso paradigmático, y presentará una estructura semejante.

Axioma 2:

Cualquier otro caso de la Teoría freudiana de la histeria será similar a Dora, su caso paradigmático, y presentará una estructura parecida.

Es casi innecesario puntualizar que la relación de similitud o parecido se refiere a las estructuras que define la teoría freudiana -no a las peculiaridades físicas o sociales de Dora-.

Debe ser contemplada en cada aplicación en particular, comparándola con Dora o con otros casos de histeria, no existiendo una noción de similitud que sea general, i.e. universal.

Finalmente, un último axioma relaciona -asocia- las representaciones -Ra- actuales a representaciones del pasado, incluso de la más temprana infancia $-R p-$ que son para Freud representaciones inconscientes privilegiadas. Este axioma relaciona sucesos, personas, actos sintomáticos o sueños con otros de cualquier momento de la historia personal de los pacientes. 
Expresándolo por medio de un diagrama:

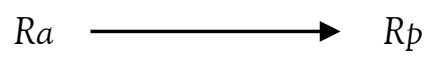

Una reflexión adicional. Como se observa, no tenemos ningún inconveniente en pensar en ejemplares efectivos -teóricos- de una teoría, que son indispensables si se pretende que actúen como guía de las investigaciones. Después de todo, los modelos parciales son modelos efectivos de una teoría previa, y poseen las funciones teóricas de ésta. No postulamos nada distinto a esto para la teoría que está en consideración. Por supuesto, esto implica una especie de realismo interno.

\subsection{Condiciones de ligadura}

La concepción estructuralista de las teorías introduce algunas relaciones entre las funciones teóricas de los modelos de la teoría, a los que llama condiciones de ligadura. Cumplen el propósito de unir a los diferentes modelos de la teoría. En el caso de la Teoría freudiana de la histeria, puede expresarse diciendo que los diferentes casos -pacientes- de histeria presentan similares elementos teóricos a los de Dora.

Esta ligadura asienta a su vez en una relación muy general que une los casos de histeria, y nos permite extender sus estructuras a nuevos casos. Es también una condición de posibilidad de todo el conocimiento psicológico. Pudiera ser expresada de la siguiente manera:

Todos los seres humanos poseen el mismo aparato psíquico, y reaccionan de la misma manera ante situaciones similares.

Sin este supuesto básico no habría teoría psicológica alguna; sólo inferencias posibles sobre la actuación individual de cada agente social específico.

\subsection{Relaciones interteóricas}

Sin pretender un análisis formal de las teorías con las que más estrechamente se encuentra relacionada la teoría psicoanalítica de la histeria, señalemos que posee elementos y objetos en común con la neurofisiología -base orgánica de la histeria-, con la fisiología en general, particularmente en lo que hace a la base orgánica de la sexualidad, y con la psicología.

Sin pretender un análisis formal de las teorías con las que más estrechamente se encuentra relacionada la teoría psicoanalítica de la histeria, señalemos que posee elementos y objetos en común con la neurofisiología -base orgánica de la histeria-, con la fisiología en general, particularmente en lo que hace a la base orgánica de la sexualidad, y con la psicología.

\subsection{La afirmación empírica pragmática}

En la afirmación empírica pragmatizada los pasos descriptos por la reconstrucción de la teoría son una suerte de instrucciones que el sujeto epistémico debe seguir para usar la teoría como una herramienta para explorar el mundo fáctico.

Cuando Freud u otro sujeto epistémico percibe que una persona dada presenta signos parecidos a los de Dora, tiene sentido que investigue en esos signos, en los actos sintomáticos o en los sueños, si experimentó y olvidó hechos traumáticos de origen sexual que son semejantes a los de Dora. Cuando esto sucede, esa persona tiene una histeria psicoanalítica. 
Si se llenan todas estas condiciones, un nuevo caso se añade al grupo abierto ${ }^{13}$ de pacientes que ya se conocen.

Aunque hablamos de individuos, no se trata de ningún relativismo, desde el momento en que quienes utilizan la teoría de Freud pertenecen a una comunidad epistémica en la que aprenden los conocimientos y habilidades que la caracteriza, y los hallazgos que realizan son puestos a prueba por otros científicos. El conocimiento que poseen deviene objetivo -intersubjetivo- en el proceso de circulación entre los miembros de la comunidad.

\section{Más allá de la teoría, las técnicas}

Dejamos por fuera de la estructura de la Teoría Psicoanalítica de la Histeria a dos elementos claves de todo el armazón del psicoanálisis.

El primero es la interpretación psicoanalítica de sueños, actos sintomáticos o síntomas, por tratarse de una herramienta de exploración del inconsciente -un método, pues-, con el mismo estatus epistémico que otros recursos técnicos, como la disección para la anatomía, el uso del telescopio para la astronomía, o la balanza. Añadiremos que este método posee su propio sistema de validación de la interpretación realizada en la forma del asentimiento del paciente, o la desaparición de los actos sintomáticos y de los síntomas.

Recordemos que los caminos que van desde las representaciones reprimidas hasta su exteriorización como sueños, síntomas o actos sintomáticos siguen una lógica de símbolos -imágenes preceptúales (símbolos) - asociadas entre sí -se dirá muy posteriormente- con las reglas de la metáfora y la metonimia. Freud apunta a otro mecanismo que no pertenece a estas reglas, puesto que lo que exterioriza aparece como lo contrario de lo que se reprime. Recordemos que Dora expresa que su padre es hombre de recursos, para exteriorizar que piensa que son escasos, aludiendo a la impotencia.

Esa Gestalt compleja que es la representación reprimida presenta múltiples facetas accesorias asociadas al suceso principal, que sin embargo llegan a exteriorizarse durante la interpretación, como sucede con el humo del sueño de Dora, que remite al aliento a tabaco de $\mathrm{K}$ en el momento en que pretende besarla.

El segundo aspecto que apartamos de la teoría es la transferencia, que Freud introduce por primera vez en este escrito como una situación que se da en la relación terapéutica, tal que para el paciente "toda una serie de sucesos psíquicos anteriores cobran de nuevo vida, pero no ya como pasado, sino como relación actual con la persona del médico" (Freud 1948b, p. 563), y cuyo manejo es central a los efectos para "evitar el retraso en la curación".

A partir de ese momento, es obvio que el psicoanálisis cuenta con una situación experimental artificial -el contexto terapéutico mismo- en el cual poner directamente a prueba sus hipótesis sobre el pasado, y los procesos de represión y asociación que provocaron.

Desde el punto de vista teórico, la transferencia puede considerarse compendiada en el axioma adicional que relaciona representaciones y vivencias actuales, ahora referida a la relación terapéutica.

Resultan claros ahora los motivos por los cuales separamos estas dos instancias, interpretación y transferencia, del cuerpo teórico de la histeria. Se trata de técnicas y métodos de exploración del inconsciente, y como tales, no forman parte del mismo.

Por otra parte, es la estrategia que sigue el propio Freud (1948b, p. 561), quien se refiere a ellos recién en el Epílogo, cuando expresa que "he omitido también toda referencia a la técnica mediante la cual extraemos el contenido de ideas inconscientes integrado en la masa total de asociaciones espontáneas de los enfermos".

\footnotetext{
${ }^{13}$ En la concepción estructuralista, las aplicaciones -sistemas físicos que son ejemplos de la teoría- constituyen un conjunto abierto, tal que pueden incorporarse nuevas aplicaciones a él, a lo largo de la historia de la teoría. En nuestra reconstrucción, preferimos hablar de grupo abierto, para señalar que se trata de agrupamiento que realizan los sujetos epistémicos, y no de una entidad abstracta.
} 


\section{Enfermedad y normalidad}

Al igual que la noción de enfermedad en la teoría fisiológica de Claude Bernard, para Freud lo normal y lo patológico no son radicalmente distintos, sino que participan de los mismos mecanismos de funcionamiento.

Según Claude Bernard, la enfermedad se produce cuando existe una desviación de los parámetros normales, provenientes de una hiperfunción o una hipofunción de los órganos. Es notable advertir que el método fisiológico de exploración de la función normal consiste en extirpar el órgano responsable de la misma, y analizar las alteraciones que origina, que coinciden con una enfermedad definida, es decir, asistimos a la producción artificial de una enfermedad, precisamente aquella que es causada por la ausencia del órgano. En el caso paradigmático de los estudios sobre la función del páncreas, su extirpación produce diabetes. El método se completa porque una vez establecida la hipótesis del aporte fisiológico de un órgano dado, se corrobora si cura restituyéndolo si se lo extirpó en la forma de extracto, etc.-, o de provocar su hiperfunción, que debe causar trastornos inversos a los de la enfermedad de su carencia. Nuevamente, en el caso del páncreas, la inyección de insulina sustituye al páncreas, normalizando los niveles de azúcar, y su exceso produce hipoglucemia.

Similarmente, para Freud los mecanismos de la histeria y de la normalidad no difieren entre sí, de tal manera que como en la fisiología del páncreas, puede investigar el funcionamiento normal del psiquismo estudiando sus enfermedades. Cuando Freud habla de la histeria, nos informa también acerca de los mecanismos normales del aparato psíquico, y de su desviación en esta enfermedad.

No es casual entonces que la interpretación correcta del material emergente durante el análisis y su corroboración por parte del paciente conduzca a la desaparición de los síntomas histéricos y de los actos sintomáticos, y por lo tanto a la curación.

Cuando la interpretación hace consciente a la representación reprimida -se exterioriza como recuerdo- el paciente cura, puesto que al dejar de reprimirse se restaura la psicofisiología normal, y ya no da lugar para los síntomas.

\section{El trasfondo teórico de la histeria}

Por supuesto, este no es el primer artículo de Freud, ni las primeras reflexiones teóricas que formula. Sin mencionarlas explícitamente -o demasiado ocasionalmente- sus postulaciones deben comprenderse en un trasfondo teórico que abarca toda la teoría psicoanalítica tal como estaba formulada por esa época, y que no ocupan un lugar en la presente reconstrucción. ${ }^{14}$

Me refiero a la postulación de una estructura psíquica, la noción de libido, o el complejo de Edipo.

Aunque todas estas nociones son un conocimiento presupuesto cuya reconstrucción no es el propósito de este articulo, se las caracterizará brevemente dentro del marco teórico introducido hasta este momento.

En el artículo de Freud no se mencionan muchos elementos de una estructura psíquica. Ya vimos que la noción de inconsciente aparece como aquellas representaciones que se reprimen, y que Freud obvia la noción de conciencia, mencionando simplemente que en caso contrario se recuerdan.

En cuanto a la noción de libido, que introduce años antes, ${ }^{15}$ podemos verla como una función de la sexualidad, que no juega un rol significativo en este artículo.

El complejo de Edipo está someramente mencionado a raíz de las relaciones de Dora con su padre. Sin intentar su reconstrucción, sugeriré que puede comprenderse apelando a un esquema

\footnotetext{
${ }^{14}$ La teoría psicoanalítica experimentó varios desarrollos y cambios a lo largo del tiempo. Me referiré exclusivamente a los que preceden al artículo sobre Dora.

${ }^{15}$ El término libido aparece por primera vez en el escrito La neurastenia y la neurosis de angustia de 1894, a propósito de los "hombres que pasan, como las mujeres, por un período climatérico, contrayendo una neurosis de angustia al tiempo que declina su potencia y aumenta su libido", especificando que "la excitación sexual se convierte en estímulo psíquico, en libido, y provoca el impulso hacia el acto específico".
} 
interpretativo similar al esbozado, en el que los elementos que figuran en él son especificaciones de los de la teoría de la histeria, personas, hechos, representaciones, represión, etc.

\section{La práctica psicoanalítica}

Habíamos ya mencionado a la afirmación empírica de la teoría, que expresa la posibilidad de extender el caso paradigmático a otros casos, señala al mismo tiempo los pasos que sigue Freud cuando inventadescubre la teoría, y cuando se aplica, es decir, establece los pasos de la génesis y el uso de la teoría.

Quizás no es lo suficientemente explícito que mencionar en este contexto las características del uso de la teoría, es una manera de indicar que el diagnóstico psicoanalítico sigue esas mismas etapas.

Y, por último, que, al hacer de un paciente dado, un histérico psicoanalítico, cubriendo en la investigación clínica las fases estipuladas por la afirmación empírica -diagnosticándolo como tal- las sucesivas corroboraciones que recibe el analista por parte del paciente son de tal índole que hacen pasar de inconsciente a conciente el material reprimido, lo cura.

Génesis de la teoría, diagnóstico y curación psicoanalítica coinciden en su estructura en la afirmación empírica pragmática que surge de reconstruir la teoría como ejemplares, siguiendo el texto de su ejemplar paradigmático, Dora.

\section{Addenda}

Nuestro camino nos ha llevado desde una exposición sucinta del caso Dora, hasta una reconstrucción nominalista de la teoría psicoanalítica de la histeria.

En nuestras investigaciones, constatamos que la secuencia de pasos que sigue Freud cuando hace de Dora su caso paradigmático de histeria psicoanalítica, notablemente, tienden a coincidir con la sucesión de las etapas que -según la concepción estructuralista- se requieren para hacer una afirmación empírica dentro de una teoría -usarla-.

Si bien la afirmación empírica permite reconstruir el uso que hace un científico de su teoría cuando explora su campo de ejemplares, en nuestro análisis notamos que es una herramienta central a la hora de comprender asimismo la etapa de constitución de la teoría, de su génesis.

Esta constatación es central a la hora de establecer la imposibilidad de postular que la teoría pueda ser caracterizada adecuadamente mediante modelos abstractos, sin interpretación, puesto que comienza con ejemplares empíricos, y en la progresiva construcción de la teoría nunca pierden su contenido fáctico. Mal puede, entonces, el metateórico señalar que en su núcleo, en aquello que es su estructura constitutiva, se encuentran modelos vacíos, matemáticos.

Por lo contrario, nos convence de que si pretendemos hacer justicia a lo que una teoría es, debemos ceñirnos a la reconstrucción de esas estructura empíricas que comienzan con elementos que no pertenecen a la teoría en cuestión -no-teóricos-, a los que se les añaden elementos teóricos, que finalmente cumplen determinados axiomas legaliformes que los relacionan entre sí.

Una reconstrucción, en síntesis, de ejemplares de la teoría, que son primeramente parciales, luego potenciales, y finalmente, ejemplares actuales, sin salir nunca de la caracterización de sistemas físicos, y sin apelar, por lo tanto, a modelos matemáticos.

Pudimos caracterizar entonces a la teoría freudiana de la histeria mediante sus ejemplares, sus ligaduras, y sus relaciones interteóricas, tal que:

$\mathrm{TFH}=\left\langle\mathbf{I}_{\mathrm{pp}}, \mathrm{I}_{\mathrm{p}}, \mathrm{I}, \mathrm{C}, \mathrm{L}\right\rangle$ siendo Dora $\mathbf{I}_{\mathrm{o}}$ en la que:

i. $\quad I_{p p}$ son ejemplares parciales

ii. $\mathbf{I}_{\mathbf{p}}$ son ejemplares potenciales

iii. I son ejemplares actuales

iv. Io $_{\mathrm{o}}$ son ejemplares paradigmáticos, en el tiempo inicial 0 de la teoría: Dora

v. C son condiciones de ligadura

vi. L son relaciones interteóricas 
No hace falta más para caracterizarla. Una teoría fáctica no comienza con, ni implica a la presencia de esas estructuras matemáticas que se pensaban indispensables, y que constituirían -supuestamente- el núcleo de la experiencia, su condición de posibilidad.

Mostramos asimismo que es el conocimiento estructural de los ejemplares paradigmáticos el que posibilita extenderlo hacia otros casos, mediante la captación de semejanzas estructurales entre éstos y otros casos que se presenten a la experiencia de un sujeto epistémico, su condición de posibilidad.

Aunque empleamos un lenguaje general usando letras tales como $\mathbf{I}, \mathbf{I}_{\mathrm{pp}}$, palabras como ejemplares, ligaduras, etc, que no apuntan a un individuo, siempre estamos describiendo a Dora, el ejemplar paradigmático, y con esto, a cualquier otro caso de histeria, incluyendo aquellos de ficción. ${ }^{16}$

Quizás esta sea la última etapa de ese proceso de simplificación y de generalización que comienza con los apuntes diarios de la consulta de Freud, sigue con el artículo en el que los resume, y culmina con una reconstrucción que la hace apta para hablar de cualquier otro caso de histeria. Un proceso que va desde una descripción muy detallada de los casos, hasta las formas muy generales de la filosofía de la ciencia.

Haciéndolo, llegamos a un lenguaje y de estructuras que nos permite describir cualquier caso posible de histeria, incluyendo casos de ficción. En esto no difiere de lo que sucede en física o en otras disciplinas, en las que los estudiantes se entrenan en ocasiones por medio de ejercicios de lápiz y papel, sin necesidad de acudir a los laboratorios.

Cuando hablamos de casos de ficción -imaginarios- no renegamos del nominalismo. Ellos existen como sucesos físicos en la forma de lenguaje-de-pensamiento ${ }^{17}$ de un sujeto epistémico que los propone, o como enunciados escritos o verbalizados.

No sólo los casos de ficción desafían al nominalismo. La presencia de ejemplares potenciales de la reconstrucción define el estatus ontológico del problema, desde el momento en que, como posibilidades que son, pudieran no referir a entidades espacio-temporales. Desde el punto de vista nominalista, la respuesta no difiere demasiado de la anterior: atribuir potencialmente elementos teóricos a un paciente -y a cualquier sistema físico de cualquier teoría- es una hipótesis adelantada por el psicoanalista, que se encuentra justificada si el paciente se comporta según lo expresan las leyes de la teoría -i.e. las representaciones reprimidas surgen durante el tratamiento-. Esto implica que mientras los ejemplares parciales y actuales refieren a sistemas empíricos -el paciente-, los ejemplares potenciales poseen la existencia de un enunciado hipotético en "lenguaje-de-pensamiento", o expresado en forma escrita o verbal.

Advertimos, tal como lo expresamos al comienzo, que en la reconstrucción se conservan elementos centrales del estructuralismo, vertidos con un lenguaje -y por ende con una ontología- de sistemas espacio-temporales, cumpliéndose, tal como se propuso desde los primeros escritos del estructuralismo, la estrategia nominalista de Wittgenstein para el uso de la teoría. Un uso que coincide con el diagnóstico, el tratamiento, y la curación de los pacientes, ya que hacer de un paciente un histérico psicoanalítico, implica hacer su diagnóstico pleno como tal, corroborándose mediante el recuerdo de las representaciones reprimidas, que según explicitáramos, restituye la fisiología normal del sistema, y por ende, la curación.

Aunque divergente de la presentación estándar, no constituye todavía una heterodoxia que se aparte radicalmente del estructuralismo. Cada tanto, aparecen manifestaciones que van en el mismo sentido, aunque no se desarrollen integralmente. Así, Ulises Moulines manifiesta que:

\footnotetext{
${ }^{16}$ Diferimos de la opinión de Balzer y Marcou, cuando expresan que los modelos potenciales describen a Dora o a otro paciente: "Constraints express assumptions of identity or stability 'across' different models. In the present case such an assumption may be stated for association: if two events are associated in one potential model (i.e. for the person described by that model) then they also are associated in any other potential model describing any other person" (Balzer \& Marcou 1989, p. 22). No hay manera de que un modelo abstracto pueda describir un caso de la teoría de Freud; como acotáramos anteriormente; toda descripción presenta, entre otras especificaciones, constantes de individuos, alejándose entonces de los modelos abstractos. Se trata de un error categorial, similar al de expresar que $2+2=4$ describe a las cuatro manzanas que están sobre la mesa.

${ }^{17}$ Uso "lenguaje-de-pensamiento" en el mismo sentido que Neurath, cuando sostiene: "No hablamos de 'pensamiento' si no directamente de 'lenguaje-de-pensamiento', es decir, de enunciados como sucesos físicos” (Neurath 1983, p. 67).
} 
Y si autores como Goodman, Field y otros tienen razón, entonces en realidad no necesitamos esos términos (los matemáticos) nunca. Podríamos prescindir de ellos cuando se trata del conocimiento de la realidad empírica (o sea del "genuino" conocimiento) y nos podríamos ahorrar los quebraderos de cabeza metafísicos que nos plantean. (Moulines 1998, p. 154)

También sostiene que "[no] es absurdo imaginarse lo esencial de MEM [Metodología estructuralista metacientífica] reproducido en el marco general de un sistema nominalista (lo bastante potente) o de uno intuicionista" (Moulines 1998, p. 148).

Coincidimos totalmente. Creemos, en efecto, que podemos prescindir de ellos, y que no es absurdo pensar en reconstruir teorías en el marco general de un sistema nominalista.

Asimismo, coincidimos con el comentario que hace, a propósito de la naturaleza ontológica de las matemáticas: "El debate sigue abierto, y no es éste el lugar para aventurar nada sustancial sobre el mismo" (Moulines 1998, p. 154).

Nuestra propuesta constituye una respuesta a esas preocupaciones, tomando una posición decidida por el nominalismo, relegado por las posiciones platonizantes que campean en filosofía de las matemáticas y la lógica, y que se han asentado -innecesariamente- en filosofía de la ciencia.

Quizás pueda sonar extraña en un mundo filosófico en el que platonismo no se discute. Sin embargo, entronca con los orígenes de la tradición en filosofía de la ciencia de la que todos somos herederos, la del Círculo de Viena.

Como lo expresa Otto Neurath: "Dado que toda la filosofía moderna tiene sus orígenes en los Escolásticos, no es sorprendente que el empirismo lógico también sea la continuación de ciertos precursores escolásticos, los nominalistas" (Neurath 1936, v.i. 1982, p. 165. Traducción de C.L.).

En ellos nos reconocemos, luego de un largo camino teórico que comienza cuestionando la existencia de entidades abstractas.

\section{Bibliografía}

Appignanesi, L. y J. Forrester (2000), Freud's Women, London: Penguin Books.

Balzer, W. y P. Marcou (1989), "A Reconstruction of Sigmund Freud's Early Theory of the Unconscious", en Westmeyer, H. (ed.), Psychological Theories from a Structuralist Point of View, Berlin/Heidelberg/New York: Springer, pp. 13-31.

Balzer, W., Moulines, C. U. y J. D. Sneed (1987), An Architectonic for Science - The Structuralist Program, Dordrecht: Reidel. (Versión castellana de Pablo Lorenzano: Una arquitectónica para la ciencia. El programa estructuralista, Bernal: Universidad Nacional de Quilmes, 2012.)

Brambrough, R. (1966) "Universals and Family Resemblance", en Pitcher, G. (ed.), Wittgenstein, New York: Anchor Books, pp. 186-205.

Carnap, R. (1956), "Empiricism, Semantics, and Ontology", en Carnap, R., Meaning and Necessity, Chicago: The University of Chicago Press, 2a ed. aumentada, pp. 205-221.

Carnap, R. (1958), "The Methodological Character of Theoretical Concepts”, en Feigl, H. y M. Scriven (eds.), Minnesota Studies in the Philosophy of Science, vol. I, Foundations of Science and the Concepts of Psychology and Psychoanalysis, Minneapolis: University of Minnesota Press, pp. 38-76.

Díez, J. A. y C. U. Moulines (1997), Fundamentos de filosofía de la ciencia, Barcelona: Ariel.

Field, H. (1980), Science Without Numbers: A Defence of Nominalism. Princeton, NJ: Princeton University Press; Oxford: Blackwell.

Frege, G. (1892), "Über Sinn und Bedeutung", Zeitschrift für Philosophie und philosophische Kritik 100: 25-50. (Versión inglesa: "On Sense and Reference", en Geach, P. and M. Black (eds.), Translations from the Philosophical Writings of Gottlob Frege, Oxford: Basil Blackwell, 1960, $2^{a}$ ed., pp. 56-78.) 
Frege, G. (1918-1919), “Der Gedanke. Eine logische Untersuchung”, Beiträge zur Philosophie des Deustchen Idealism I: 5877. (Versión inglesa de Anthony M. y Marcelle Quinton: “The Thought: A Logical Inquiry”, Mind 65(259) (1956): 289-311.)

Freud, S. (1893), "Quelques considérations pour une étude comparative des paralysies motrices organiques et hystériques", Archives de Neurologie 26(77): 29-43.

Freud, S. (1948a), Obras completas, Madrid: Biblioteca Nueva.

Freud, S. (1948b), “Análisis fragmentario de una histeria”, en Freud (1948a, vol. II), pp. 513-566.

Freud, S. (2000), The Standard Edition of the Complete Psychological Works or Sigmund Freud (traducido del alemán bajo la dirección general de James Strachey en colaboración con Anna Freud, 24 vols.), New York: W. W. Norton \& Co.

Grünbaum, A. (1984), The Foundations of Psychoanalysis, Berkeley: University of California Press.

Goodman, N. y W. V. Quine (1947), “Towards a Constructive Nominalism”, Journal of Symbolic Logic 12: 105-122.

Goodman, N. (1972), Problems and Projects, Indianapolis/New York: The Babbs Merril Company, Inc.

Lorenzano, C. (1982), La estructura psicosocial del arte, México: Siglo XXI.

Lorenzano, C. (2001), “Teorías científicas, ontología y lenguaje”, en Sagüillo, J. M., Falguera, J. L. y C. Martínez (eds.), Teorias formales y teorías empiricas, Santiago de Compostela: Publicaciones de la Universidad de Santiago de Compostela, pp. 623-637.

Lorenzano, C. (2002), "La estructura pragmática de la ciencia”, Comunicación al Tercer Encuentro Iberoamericano de Metateoría Estructuralista, Granada.

Moulines, C. U. (1982), Exploraciones metacientificas, Madrid: Alianza.

Moulines, C. U. (1996), “Structuralism: The Basic Ideas”, en Balzer, W. y C. U. Moulines (eds.), Structuralist Theory of Science, Berlin: Walter de Gruyter, pp. 1-13.

Moulines, C. U. (1998), “Esbozo de ontoepistemosemántica”, Theoria 13(31): 141-159.

Nagel, T. (1965), "Physicalism”, Philosophical Review 74(3): 339-356.

Neurath, O. (1931a), "Physicalism: The Philosophy of the Viennese Circle”, The Monist 41: 618-623.

Neurath, O. (1931b), "Physicalism”, Scientia 50: 297-303.

Neurath, O. (1983), Philosophical Papers $1913-1946$ (ed. y trad. por Robert Cohen y Marie Neurath), Dordrecht/Boston: Reidel.

Peirce, C.S. (1966), "Letters to Lady Welby”, 31 Jan 1909, en Wiener, P. P. (ed.), Charles S. Peirce: Selected Writings (Values in a Universe of Chance), New York: Dover, p. 406.

Rodríguez-Pereyra, G. (2000), Resemblance Nominalism. A Solution to the Problem of Universals, Oxford: Oxford University Press.

Sneed, J.D. (1971), The Logical Structure of Mathematical Physics, Dordrecht: Reidel.

Stegmüller, W. (1973), Theorienstrukturen und Theoriendynamik, Heidelberg: Springer.

Stegmüller, W. (1979), The Structuralist View of Theories, Berlin: Springer.

Suppes, P. (1960), “A Comparison of the Meaning and Uses of Models in Mathematics and the Empirical Sciences”, en Suppes, P., Studies in the Methodology and Foundations of Science. Selected Papers from 1951 to 1969, Dordrecht: Reidel, 1969, pp. 10-24.

Wittgenstein, L. (1958), Philosophical Investigations, Oxford: Basil Blackwell.

Wittgenstein, L. (1956), Remarks on the Foundations of Mathematics, Oxford: Basil Blackwell. 